\title{
Pre- and post-exercise nutritional practices of amateur runners in the UK: are they meeting the guidelines for optimal carbohydrate and protein intakes?
}

\author{
Louise A. McLeman ${ }^{1} \cdot$ Katy Ratcliffe $^{1} \cdot$ Tom Clifford $^{2}$ (D)
}

Received: 28 November 2018 / Accepted: 11 February 2019 / Published online: 25 February 2019

(C) The Author(s) 2019

\begin{abstract}
Purpose The aim of this study was to investigate amateur runners' knowledge and practices of the current sports nutrition guidelines for pre and post-event carbohydrate (CHO) and protein (PRO) intakes.

Methods Data was collected from 100 amateur runners using an online survey. Participants provided demographic information, a dietary recall of their intake $24(n=49)$ and $1-4 \mathrm{~h}$ before and immediately after a long-distance run $(\geq 60-90 \mathrm{~min}$ in duration) for analysis of $\mathrm{CHO}$ and PRO contents $(n=82)$. They also answered questions about their knowledge of the current $\mathrm{CHO}$ and $\mathrm{PRO}$ recommendations and their primary sources of nutrition information.

Results CHO intake 24-h pre-exercise $\left(3.3 \pm 1.7 \mathrm{~g} \mathrm{~kg} \mathrm{day}^{-1}\right)$ was lower than the currently recommended intakes of 10-12 $\mathrm{g} \mathrm{kg}^{-1}$ for effective CHO loading $(P=0.001)$. Average CHO intake $1-4 \mathrm{~h}$ pre-exercise $\left(1.2 \pm 0.6 \mathrm{~g} \mathrm{~kg}^{-1}\right)$ were within the recommended amounts $>1.0 \mathrm{~g} \mathrm{~kg}-1(P>0.05)$; however, only $60 \%$ of participants consumed $\geq 1.0 \mathrm{~g} \mathrm{~kg}^{-1}$. Post-exercise $\mathrm{CHO}$ intakes $\left(1.1 \pm 0.8 \mathrm{~g} \mathrm{~kg}^{-1}\right)$ were not different from the recommended guidelines $\geq 1.0 \mathrm{~g} \mathrm{~kg}^{-1}(P=0.190)$ but only $\sim 48 \%$ of participants achieved this target. Average PRO intake post-exercise exceeded the minimum recommended guidelines $(\geq 0.25$ $\mathrm{g} \mathrm{kg}^{-1}$ ) by $\sim 0.15 \mathrm{~g} \mathrm{~kg}^{-1}(P=0.001)$; however, only $\sim 75 \%$ of participants consumed $\geq 0.25 \mathrm{~g} \mathrm{~kg}^{-1}$. Overall, knowledge of the current $\mathrm{CHO}$ and PRO intakes pre and post-exercise were poor, with $<5 \%$ of participants selecting the correct answers. Conclusions This study suggests that amateur runners are largely unaware of the current sport nutrition guidelines and preexercise intake of CHO (24 h pre) is sub-optimal.
\end{abstract}

Keywords Running $\cdot$ Nutrition $\cdot$ Protein $\cdot$ Carbohydrates $\cdot$ Endurance exercise

\section{Introduction}

Carbohydrates are stored in the liver and muscle as glycogen [1]. During exercise, stored glycogen is broken down to glucose and used to fuel contractile activity [1]. It is widely believed that one of the main causes of fatigue during aerobic exercise is the depletion of these glycogen stores, which, depending on the intensity of the exercise, begins to occur after $\sim 60-90 \mathrm{~min}$ of aerobic exercise [1-3].

Tom Clifford

tom.clifford@newcastle.ac.uk

1 School of Biomedical Sciences, Newcastle University, Newcastle-upon-Tyne, UK

2 Faculty of Medical Sciences, Institute of Cellular Medicine, School of Biomedicine, Newcastle University, Newcastle-upon-Tyne NE2 4HH, UK
Thus, to optimize performance and recovery, current sports nutrition guidelines recommend that endurance athletes, defined as those taking part in events $\geq 30 \mathrm{~min}$ in duration [3] 'carbohydrate load' in the 1-2 days prior to endurance events $\geq 90 \mathrm{~min}$ in duration; that is, consume higher than normal amounts of carbohydrate ( $\mathrm{CHO})$ to saturate their muscle and liver glycogen stores prior to the event [2-4]. The recommended amounts are dictated by the duration of exercise; $7-12 \mathrm{~g} \mathrm{~kg} \mathrm{day}^{-1}$ of CHO if exercise is $<90 \mathrm{~min}$ in duration or $10-12 \mathrm{~g} \mathrm{~kg} \mathrm{day}^{-1}$ if $\geq 90 \mathrm{~min}$ in duration $[1,4]$.

Similarly specialized recommendations are provided for post-exercise carbohydrate intakes [15]. Indeed, Moore [15], recommends that endurance athletes consume $\mathrm{CHO}$ at a rate of $\sim 1.2 \mathrm{~g} \mathrm{~kg} \mathrm{~h}^{-1}$ to replete diminished glycogen stores following exercise, a pattern that should continue for at least $4 \mathrm{~h}$ if rapid refueling is required. However, it is important to note that if there is $\geq 8 \mathrm{~h}$ before the next exercise bout, 
then resuming normal carbohydrate intake in the next $24 \mathrm{~h}$ is considered sufficient to replenish glycogen stores [4].

Endurance athletes are also encouraged to pay special attention to their post-exercise intake of protein (PRO), given its important role in skeletal muscle repair and re-modelling $[5,6]$. The current sports nutrition guidelines recommend that $\geq 0.25 \mathrm{~g} \mathrm{~kg}^{-1}$ of PRO is consumed immediately post to maximize muscle protein synthesis (MPS) and myofibrillar remodeling following endurance exercise [5]. Protein, therefore, plays a key role in the adaption and recovery of skeletal muscle function following endurance exercise.

These targets have been developed over several decades of laboratory research and represent the most effective dietary strategies to optimize recovery and performance [4]. Despite this, research suggests professional endurance athletes find it difficult to reach the recommended pre- and post-exercise PRO and CHO intakes, either due to a lack of knowledge or difficulty in managing their dietary behaviors [7, 8]. It would, therefore, be reasonable to assume that amateur endurance athletes, especially those performing $\geq 1$ $\mathrm{h}$ day $^{-1}$, find it even more challenging to reach the current sports nutrition guidelines. In support of this contention, recent studies suggested that pre- and post-exercise intakes of PRO and CHOs are sub-optimal in amateur endurance athletes. For example, in the study by Doering et al. [9] it was found that Australian masters triathletes only consumed $0.7 \mathrm{~g} \mathrm{~kg}^{-1}$ of CHOs post-exercise, significantly below the recommended intakes for optimal glycogen repletion. Similarly, Praz et al. [10] reported that the 40 ski-mountaineers they evaluated failed to consume the recommended $10 \mathrm{~g} \mathrm{~kg} \mathrm{day}^{-1}$ of CHOs in the days leading up to an ultraendurance race, with average intakes $<5 \mathrm{~g} \mathrm{~kg} \mathrm{day}^{-1}$. The authors of both studies speculated that their findings could be due to poor nutritional knowledge or possibly compliance. This could stem from the fact that apart from athletes at the highest level, most do not have access to a qualified nutrition professional, instead relying on coaches, friends and the internet for sports nutrition advice [9]. Nonetheless, sub-optimal CHO and PRO intakes before and after training or races, especially those longer than 60-90 min, could negatively affect performance and recovery—and possibly even compromise immune function and general health $[3,5,11]$.

Because participation in amateur running events has increased exponentially in recent decades $[3,12,13]$, an examination of the dietary practices of amateur runners, specifically their $\mathrm{CHO}$ and PRO intakes around training and races is timely and warranted. To the author's knowledge, no study to date has evaluated the sports nutrition practices of amateur runners in the UK; thus, the primary aim of the present study was to examine whether amateur runners from the UK reach the current sport nutrition guidelines for pre- and post-event $\mathrm{CHO}$ and PRO intakes. A secondary objective of this study was to determine recreational runner's knowledge of these intakes and their primary sources of nutrition information. We specifically chose to focus on the CHOs and PROs over other nutrients such as dietary fat or individual vitamins, as these are the macronutrients most relevant to performance and recovery during training and competition. We hypothesized that most amateur runners would fail to meet the current guidelines for pre- and post-exercise $\mathrm{CHO}$ intakes and post-exercise PRO intakes and that their knowledge of the guidelines would be poor.

\section{Methods}

\section{Participants}

One hundred participants responded to the online survey and provided informed consent to take part in this study September-December 2017. The demographic characteristics of the participants, including body mass, were selfreported, and are presented in Table 1. The participants were recruited from local running clubs and were all amateur
Table 1 Participant characteristics

\begin{tabular}{|c|c|c|c|}
\hline & $\begin{array}{l}\text { Nutrition knowledge and } \\
\text { sources of nutrition informa- } \\
\text { tion }\end{array}$ & $\begin{array}{l}\text { Pre- and post-ex } \\
\text { CHO and post-ex } \\
\text { PRO }\end{array}$ & $24 \mathrm{~h}$ pre-ex $\mathrm{CHO}$ \\
\hline Total number of participants $(n)$ & 100 & 82 & 49 \\
\hline Male participants $(n)$ & 43 & 42 & 25 \\
\hline Female participants $(n)$ & 57 & 40 & 24 \\
\hline Mass (kg) & $\begin{array}{l}\text { M: } 73.5 \pm 10.3^{\mathrm{a}} \\
\mathrm{F}: 58.8 \pm 9.6\end{array}$ & $\begin{array}{l}\text { M: } 72.8 \pm 10.9^{\mathrm{a}} \\
\text { F: } 59.0 \pm 9.8\end{array}$ & $\begin{array}{l}\text { M: } 73.0 \pm 10.8^{a} \\
F: 59.2 \pm 9.5\end{array}$ \\
\hline Age (years) & $32 \pm 13$ & $30 \pm 13$ & $31 \pm 14$ \\
\hline Number of years running ${ }^{\mathrm{b}}$ & (1) $9 \pm 9(32)$ & (1) $10 \pm 9(32)$ & (1) $8 \pm 9(32)$ \\
\hline Number of hours run per week ${ }^{b}$ & (1) $3 \pm 2(7)$ & (1) $3 \pm 1(7)$ & (1) $3 \pm 1(7)$ \\
\hline
\end{tabular}

$M$ male, $F$ female, $C H O$ carbohydrate, $P R O$ protein

${ }^{\mathrm{a}}$ Denotes difference in body mass between males and females $(P=0.001)$

${ }^{\mathrm{b}}$ Numbers in parenthesis represent minimum and maximum values 
level-defined as not racing competitively at regional level or above. Participants were required to partake in runs of at 60-min duration each week, however. The study received ethical approval from Newcastle University.

\section{Survey}

Data was collected via an online survey (Online Surveys, Bristol, UK) that was distributed amongst running club members. The survey consisted of three sections; the first was to collect demographic information, the second to collect pre- and post-exercise dietary intakes, and the third to assess nutrition knowledge and sources of nutrition information.

Capturing pre- and post-exercise nutrition intakes required participants to fill in an open text-box describing everything that they consumed during that specific time. Participants were asked to provide; (1) a $24 \mathrm{~h}$ recall of their dietary intake prior to a race/run race; (2) details of a prerace meal consumed $\sim 2 \mathrm{~h}$ prior to a race/run and; (3) details of anything they consumed (e.g., a supplement, meal or combination) immediately or within the first $60 \mathrm{~min}$ following a race/run. Participants were encouraged to do the 24-h pre-exercise recall in-real time (e.g., before or after and actual run/race). The acute pre- and post-race intakes required participants to provide details of a 'typical' intake/ meal [9]. To increase the accuracy of the data, we also specified that the recalls should reflect intakes before runs/races lasting $\geq 60-90$ min only (e.g., $1 / 2$ marathon or a marathon distance for most) because exercise of this duration is more likely to be compromised by sub-optimal CHO loading strategies [1,3]. Participants were provided with completed examples to demonstrate the level of detail that was required, including brand names and amounts of each food/drink in grams/household measures. The first two authors screened all dietary recalls prior to analysis and excluded any that did not provide sufficient detail of the type and amount of foods consumed. Analysis was performed with a validated online dietary software tool (Intake24, Newcastle, UK).

Follow-up questions focused on knowledge of the current $\mathrm{CHO}$ and PRO intakes pre- and post-exercise. Specifically, participants were asked to select from a drop down list what the recommended intakes are for effective $\mathrm{CHO}$ loading 24 and $2 \mathrm{~h}$ before a distance run/race and what the recommended $\mathrm{CHO}$ and PRO intakes are post-race. Finally, they were asked to provide details of their main sources of sports nutrition information.

\section{Data analysis}

Data was analysed using SPSS (Version 24.0) and the level of statistical significance was set to $P<0.05$. Data were considered normally distributed according to the Shapiro-Wilk test. The recommended guidelines for pre and post-exercise $\mathrm{CHO}$ and post-exercise PRO intakes were taken from the Position of the Academy of Nutrition and Dietetics, Dietitians of Canada, and the American College of Sports Medicine: Nutrition and Athletic Performance [4]. Independent samples $T$ tests were used to compare recommended intakes to the participant's intakes. Questions relating to nutrition knowledge and sources of nutrition information are presented as frequency of responses. All data are presented as mean \pm SD unless stated otherwise and results for dietary intakes are reported relative to body mass.

\section{Results}

Due to insufficient detail provided in the pre-exercise dietary recalls (as agreed by two researchers upon inspection), data for $\mathrm{CHO}$ loading practices 24 and $1-4 \mathrm{~h}$ pre-exercise were only performed with 49 and 82 participants, respectively (see Table 1 for demographics). The remaining data were excluded from data analysis. There were no sex differences in dietary intakes or physical characteristics $(P>0.05)$ other than body mass $(P=0.001$; Table 1$)$. Thus, we grouped all participants together for analysis to increase our sample size.

\section{Pre and post-CHO and PRO intakes}

CHO intake 24-h pre-exercise was $3.3 \pm 1.7 \mathrm{~g} \mathrm{~kg} \mathrm{day}^{-1}-$ significantly lower than both the $7-12 \mathrm{~g} \mathrm{~kg} \mathrm{day}^{-1}$ recommendation for effective $\mathrm{CHO}$ loading $24 \mathrm{~h}$ before a training run or race lasting $\geq 60-90 \mathrm{~min}$ and the $5-7 \mathrm{~g} \mathrm{~kg} \mathrm{day}^{-1}$ recommendation for exercise of $\sim 1 \mathrm{~h}$ ([4]; $P=0.001$; Fig. 1). Less than $20 \%$ reported consuming $\geq 5 \mathrm{~g} \mathrm{~kg}^{-1}$ of CHOs in the 24-h pre-run (Table 2). Average CHO intake in a typical pre-race meal was $1.2 \pm 0.6 \mathrm{~g} \mathrm{~kg}^{-1}$ which is in agreement with the recommend guidelines of $\geq 1.0-4.0 \mathrm{~g} \mathrm{~kg}^{-1}$ ([1]; $P<0.05$; Fig. 1; Table 2). Post-exercise CHO intakes ( $<60 \mathrm{~min}$ post) were not different to the current guidelines ( $1.1 \pm 0.8 \mathrm{~g} \mathrm{~kg}^{-1}$ vs. $1.2 \mathrm{~g} \mathrm{~kg}^{-1}$; [5], $P=0.190$; Fig. 1$)$; however, less than $50 \%$ of participants met this target (Table 2). Average post-exercise PRO intakes ( $<60$ min post) exceeded the minimum recommended guidelines $\left(\geq 0.25 \mathrm{~g} \mathrm{~kg}^{-1}\right.$; [5]) by $\sim 0.15 \mathrm{~g} \mathrm{~kg}^{-1}$ ( $P=0.001$; Fig. 1$)$; however, $25 \%$ of the participants consumed $\leq 0.25 \mathrm{~g} \mathrm{~kg}^{-1}$ (Table 2).

\section{Knowledge of the recommendations}

Only $4 \%$ of participants correctly identified the pre-exercise recommendations for $\mathrm{CHO}$ loading; $11 \%$ selected an incorrect answer $\left(<10 \mathrm{~g} \mathrm{~kg}^{-1}\right)$ and $85 \%$ selected 'I don't know'. For post-exercise intakes, only $4 \%$ correctly identified the recommend PRO intakes and only $1 \%$ identified 
Fig. 1 a Carbohydrate (CHO) intake $24 \mathrm{~h}(n=49)$ and $\sim 2 \mathrm{~h}$ pre-run/race $(n=82)$ vs. recommended intakes [4]. b CHO and protein (PRO) intakes post-run/ race vs. recommended intakes $(n=82)$ [4]. *Different to recommended intakes; $P<0.05$
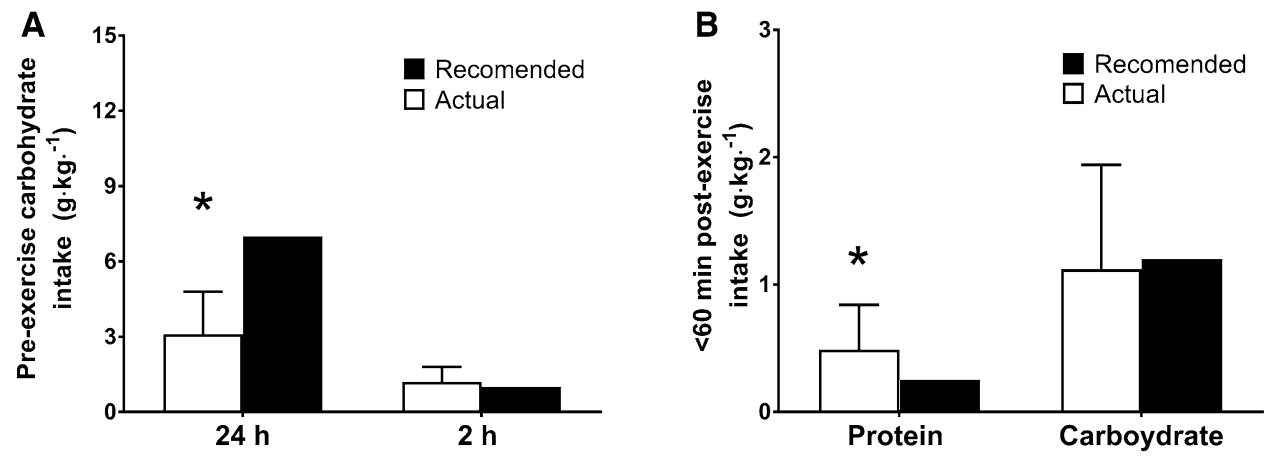

Table 2 The $\%$ of participants meeting the minimum recommendations for pre- and post-exercise carbohydrate and post-exercise protein intakes

\begin{tabular}{ll}
\hline Variable & a of participants meeting \\
\hline 24-h pre-exercise carbohydrate intake $\left(5 \mathrm{~g} \mathrm{~kg}^{-1} ; n=49\right)$ & 19 \\
$1-4$ h pre-exercise carbohydrate intake $\left(1 \mathrm{~g} \mathrm{~kg}^{-1} ; n=82\right)$ & 60 \\
Post-exercise carbohydrate intake $\left(1 \mathrm{~g} \mathrm{~kg}^{-1} ; n=82\right)$ & 48 \\
Post-exercise protein intake $\left(0.25 \mathrm{~g} \mathrm{~kg}^{-1} ; n=82\right)$ & 75 \\
\hline
\end{tabular}

${ }^{a}$ Data in parenthesis indicates minimum recommended amounts, based on [4]

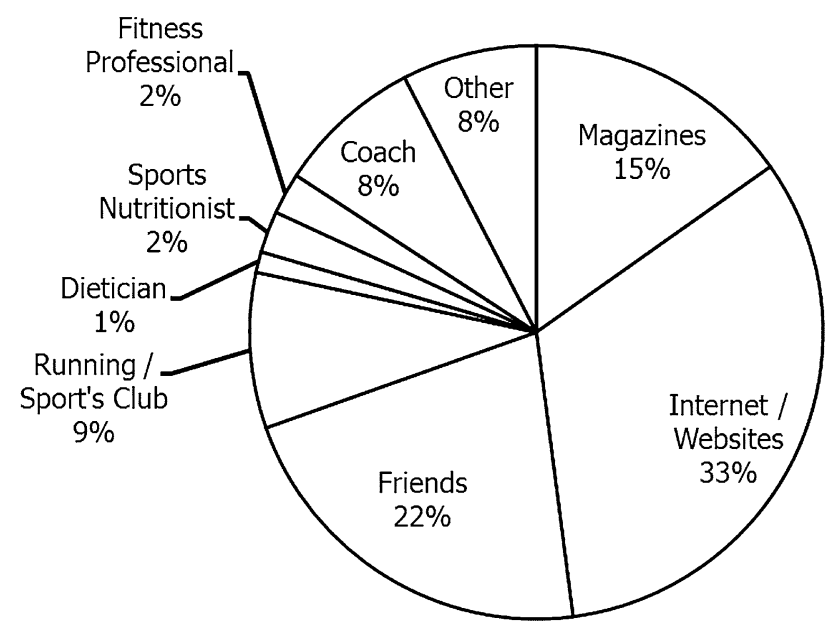

Fig. 2 Frequency of responses (\%) for participants main source of sports nutrition information $(n=100)$

the recommended $\mathrm{CHO}$ intakes. The remaining respondents selected either 'I don't know' ( $89 \%$ for both) or answered incorrectly.

\section{Sources of sports nutrition information}

Figure 2 provides the frequency of responses (\%) for the participants main source of sports nutrition information. The most frequently selected response was the internet, followed by friends and magazines. Fitness professional, sports nutritionist and dietitian were the most infrequent answers.

\section{Discussion}

The main finding of this study is that amateur endurance runners do not consume sufficient CHOs to optimize glycogen stores in the $24 \mathrm{~h}$ before distance runs or events. Most reach the current recommended guidelines for PRO intake post-exercise, but only half reach the current guidelines for post-exercise $\mathrm{CHO}$ intakes. Overall, the runners exhibited a poor knowledge of the pre- and post-exercise guidelines for optimal PRO and CHO intakes, with less than $5 \%$ correctly identifying the recommended intakes.

This is not the first study to report that dietary $\mathrm{CHO}$ intakes are sub-optimal in amateur endurance athletes. Praz et al. [10] reported that the average $\mathrm{CHO}$ intake of 40 ski-mountaineers was $\sim 4.5 \mathrm{~g} \mathrm{~kg} \mathrm{day}^{-1}$ in the 4 days leading up to an ultra-endurance event. Akin to the average $\mathrm{CHO}$ intakes reported in our study before an event $\left(3.3 \mathrm{~g} \mathrm{~kg} \mathrm{day}^{-1}\right)$, these intakes are significantly below the current guidelines, which recommend $\mathrm{CHO}$ intakes are increased to $10-12 \mathrm{~g} \mathrm{~kg} \mathrm{day}^{-1} 36-48 \mathrm{~h}$ before events $>90 \mathrm{~min}$ in duration to optimize glycogen stores and performance $[4,14]$. Similarly poor use of effective CHO loading practices was reported by Sparks et al. [15] who found that only $48 \%$ of $\sim 2500$ cyclists taking part in a $94.7 \mathrm{~km}$ road race in South Africa intended to CHO load in the 2-3 days leading up to the race. Because actual $\mathrm{CHO}$ intakes were not recorded, it is unclear whether those intending to $\mathrm{CHO}$ load reached the recommended sports nutrition guidelines. Wardenaar et al. [16] did not assess $\mathrm{CHO}$ intake in the days before an event, but did report 
that the habitual $\mathrm{CHO}$ intake of ultra-marathon runners was only $4.4 \pm 1.3 \mathrm{~g} \mathrm{~kg} \mathrm{day}^{-1}$, which is below the 5-7 $\mathrm{g} \mathrm{kg} \mathrm{day}^{-1}$ intakes recommended for moderate training [4].

The fact that so few of the participants in the present study consumed $\geq 5 \mathrm{~g} \mathrm{~kg} \mathrm{day}^{-1}$ of CHOs 24 -h pre-exercise, suggests that many do not even reach the lower end of recommended $\mathrm{CHO}$ intakes for moderate training equivalent to $60 \mathrm{~min} \mathrm{day}^{-1}\left(5-7 \mathrm{~g} \mathrm{~kg} \mathrm{day}^{-1}\right.$,[4]). However, given that the average time each participant trained in this study was $3 \mathrm{~h} \mathrm{wk}^{-1}$, it could be argued that in for this group of amateur runners, their $\mathrm{CHO}$ intakes might have actually been sufficient for replenishing muscle and liver glycogen stores between training sessions, and therefore, adequate for fueling training runs of 60-90 min. This is not to say that these intakes would be optimal prior to a race of $<90$ min duration; Burke et al. [1] recommends intakes of $\geq 7 \mathrm{~g} \mathrm{~kg} \mathrm{day}^{-1}$ 24-36 $\mathrm{h}$ prior to a race of this duration, owing to the high intensity of races and therefore high reliance of glycogen. Indeed, it is well established that consuming adequate $\mathrm{CHO}$ before exercise of this intensity and duration can enhance performance; thus, the inadequate intakes reported could compromise performance, as well as the physiological adaptations associated with training at high intensities, such as enhanced CHO oxidation [2]. This could mean that some of these athletes are reliant on fat oxidation for events of this intensity and duration, which is known to impair endurance performance [18].

Because we only asked participants to describe intakes prior to a 60-90 min training run or race, we cannot determine whether the dietary recalls were typical of their prerace or pre-training run, and whether these differed substantially. This is the same method used in previous studies of this nature [9]; however, we encourage future research in this area to ask for dietary recalls for both race and training runs-including specific types, to specifically determine if amateur runners adequately fuel prior to races.

To maximize liver and muscle glycogen stores, the latter of which might be partially depleted following an overnight fast, athletes are recommended to consume a $\mathrm{CHO}$ rich meal (1-4 $\left.\mathrm{g} \mathrm{kg}^{-1}\right) 1-4 \mathrm{~h}$ prior to a race $[1,4,14]$. In the present study, the number of participants meeting the recommendations was far lower than those reported by Wardenaar and colleagues [16] in a sample of ultra-marathon runners. In their study, CHO intake was $\sim 1.2 \mathrm{~g} \mathrm{~kg}^{-1} 3-4 \mathrm{~h}$ pre-race with $\sim 88 \%$ of respondents consuming $\geq 1.0 \mathrm{~g} \mathrm{~kg}^{-1}$. There are several possible reasons for the discrepancy intakes in the present study and the study of Wardenaar et al. [16] including differences in dietary analysis techniques and participants. Perhaps the most notable is the fact that in their study the pre-exercise $\mathrm{CHO}$ intake was specific to a $60 \mathrm{~km}$ running race, whereas the present study instructed the participants to detail a meal before a run or race event lasting $\geq 60-90 \mathrm{~min}$. It would be reasonable to assume that the higher number of participants reaching the guidelines in the study of Wardenaar et al. [16] was, at least in part, influenced by the distance of the upcoming race.

The participants demonstrated a poor knowledge of the recommended post-exercise PRO intakes, with the majority of respondents selecting 'I don't know'. In a similar study with amateur triathletes from Australia [9], knowledge of post-exercise PRO intakes were also poor; however, the number of respondents selecting 'I don't know' was only $\sim 43 \%$, suggesting they had a better knowledge of the sports nutrition guidelines then the participants in the present study. Nonetheless, despite their poor knowledge of the guidelines, most of the participants in the present study consumed $\geq 0.25 \mathrm{~g} \mathrm{~kg}^{-1}$, suggesting that irrespective of knowledge, many amateur runners habitually consume sufficient amounts of PRO following running exercise.

The amateur runners in the present study reported consuming $\geq 1 \mathrm{~g} \mathrm{~kg}^{-1}$ of $\mathrm{CHO}$ immediately following endurance exercise. While this is in line with the current $\mathrm{CHO}$ recommendations for rapid restoration of glycogen stores following exercise $\left(1.2 \mathrm{~g} \mathrm{~kg}^{-1}\right.$; [5]) and similar to the amounts reported by Doering et al. [9] for young amateur triathletes $\left(1.1 \mathrm{~g} \mathrm{~kg}^{-1}\right)$ several participant's reported intakes above the lower end of the recommendations $\geq 1.0 \mathrm{~g} \mathrm{~kg}^{-1}$ [1]. Doering et al. [9] did not describe the number of participant's that reached the $\geq 1.0 \mathrm{~g}$ in their present study for comparisons with the present study. However, given the wide-variability of intakes in their study (SD $0.7 \mathrm{~g} \mathrm{~kg}^{-1}$ ) it would be reasonable to assume that a high number of participants were also not reaching the current recommendations. Interestingly, they found that older triathletes ( $\geq 50$ years old) failed to reach the guidelines for post-exercise $\mathrm{CHO}$ intakes, only consuming $0.7 \mathrm{~g} \mathrm{~kg}^{-1}$ immediately post-exercise. We did a sub-analysis on our data to analyze for age differences but did not observe any significant differences in post-exercise $\mathrm{CHO}$ or PRO intakes in those $\geq 50$ years old in the present study (data not shown).

There are several possible reasons why the amateur runners in this study had sub-optimal CHO intakes, especially in the $24 \mathrm{~h}$ before a race. Firstly, given that only $4 \%$ of participants were able to correctly identify the recommended intakes for CHO loading prior to a race or training session $>60-90$ min, many might simply lack the knowledge necessary to adequately fuel themselves. However, lack of knowledge cannot be the only factor, because knowledge of post-exercise $\mathrm{PRO}$ and $\mathrm{CHO}$ intakes were equally poor but half or more of the participants still reached the current guidelines. Therefore, factors such as financial and time constraints associated with purchasing and preparing foods and concerns about weight management are likely contributing factors. Some could have also been deliberately consuming fewer CHOs. Low or reduced $\mathrm{CHO}$ diets have grown in popularity in recent decades, receiving enormous media 
attention [17]. It is possible that some of the runners in the present study were following a low $\mathrm{CHO}$ diet, erroneously believing that it might benefit performance [18]. The influence of these and other factors on the dietary intakes of amateur runners should be explored in future studies.

The top three sources of sports nutrition information for the amateur runners were internet websites magazines $(21 \%)$ and friends (1\%); only $1 \%$ of the sample reported that a qualified nutrition professional was their main source of sports nutrition information. These findings are not dissimilar to others that have surveyed amateur athletes on their main source of nutrition information. For example, in Tsitsimpikou et al. [19] of the 329 gym members surveyed, over 50\% said that most of their advice came from personal trainers or friends. More recently, Doering et al. [9] reported that only $12.7 \%$ of amateur triathletes consulted a sports dietitian for nutrition advice, with nearly half relying either on their own knowledge or magazines, websites or friends. This is contrast to the findings with elite athletes, who tend to report that sports dietitians are their main source of nutrition information. For example, Devlin \& Belski [20] reported that $98 \%$ of the professional football players they surveyed indicated that a sports dietitians was their primary source of nutrition information. Others have also indicated that most elite athletes, even at the collegiate level, have access to a sports nutrition professional for advice [21]. Because this study, and the others mentioned $[9,19]$ suggest that magazines and the internet are primary sources of sport nutrition information for amateur athletes, it is important that accurate and useful information is made available via these platforms. Organizers of events and governing bodies might also help to improve sport nutrition knowledge of the general public by providing easy to understand resources both at events and on their websites/social media platforms.

The main limitation of this study is that the findings are reliant on self-reported dietary intakes and this should be taken into consideration when interpreting these findings. Great care was taken to remove those that did not provide sufficient detail; however, this does not control for that fact individuals commonly under report their dietary intakes and, therefore, it is probable that the runners in this study actually consume more than the values presented [7]. Nonetheless, even if the levels of under-reporting was a high as 30-50\% for some athletes-as suggested by some [7], then many of the participants would still not have reached the current guidelines for $\mathrm{CHO}$ intake in the $24 \mathrm{~h}$ pre-exercise. Another potential limitation is the fact that we asked participants to describe their 'typical' intakes before and after a recent run of 60-90 min duration. This could have been several days for some of the participants and, therefore, led to inaccuracies.

Another limitation is the relatively low sample size and the fact that all of the amateur runners surveyed were from the UK. Thus, the findings of the present study might not translate to other countries and cultures, where access to certain types of foods and resources such as the internet and magazines might not be as readily available as in the UK and other western countries. It is also important to consider the influence of how the data are presented to the participants. We opted to present the dietary intakes of $\mathrm{CHO}$ and PRO relative to body mass, as is now common in scientific literature and amongst sports nutritionists; however, this may have been difficult for the participants to comprehend. If, for example, we had presented the data as absolute values, e.g., grams per day, their knowledge may have been adequate. This should be considered in future research. A strength of this study, however, is that it is the first to report the $\mathrm{CHO}$ and PRO intakes of amateur runners and, unlike the previous studies in amateur athletes $[9,10,15,16]$, reports both the pre- and post-exercise intakes, at the most relevant times for performance and recovery.

In conclusion, this is the first study to demonstrate that many amateur runners do not meet the pre- and post-exercise guidelines for optimal CHO and PRO intakes. This is likely due, at least in part, to the fact they have poor knowledge of the current guidelines and often have to rely on the internet and friends for their nutrition advice, as opposed to qualified professionals. Notwithstanding these constraints, the suboptimal fueling and recovery practices observed in this study could affect performance and the general health of amateur runners suggesting that more education and resources should be readily available to this population.

\section{Compliance with ethical standards}

Conflict of interest The authors did not receive funding for this research and declare that they have no competing interests.

Ethics approval This study and all procedures were in approved by Newcastle University Faculty of Medical Sciences Ethics Committee.

Informed consent All participants were informed of the purpose of the study and provided consent.

OpenAccess This article is distributed under the terms of the Creative Commons Attribution 4.0 International License (http://creativeco mmons.org/licenses/by/4.0/), which permits unrestricted use, distribution, and reproduction in any medium, provided you give appropriate credit to the original author(s) and the source, provide a link to the Creative Commons license, and indicate if changes were made.

\section{References}

1. Burke LM, Hawley JA, Wong SH, Jeukendrup AE (2011) Carbohydrates for training and competition. J Sport Sci 29:S17-S27 
2. Hawley JA, Schabort EJ, Noakes TD, Dennis SC (1997) Carbohydrate-loading and exercise performance. Sport Med 24:73-81

3. Jeukendrup AE (2009) Nutrition for endurance sports: marathon, triathlon, and road cycling. J Sport Sci 29:S91-S99

4. Thomas DT, Erdman KA, Burke LM (2016) Position of the academy of nutrition and dietetics, dietitians of canada, and the american college of sports medicine: nutrition and athletic performance. J Acad Nutr Diet 116:501-528

5. Moore DR (2015) Nutrition to support recovery from endurance exercise: optimal carbohydrate and protein replacement. Curr Sports Med Rep 14:294-300

6. Moore DR, Camera DM, Areta JL, Hawley JA (2014) Beyond muscle hypertrophy: why dietary protein is important for endurance athletes. App Physiol Nutr Metab 39(9):987-997

7. Burke LM, Cox GR, Cummings NK, Desbrow B (2001) Guidelines for daily carbohydrate intake. Sports Med 31:267-299

8. Heikura IA, Burke LM, Mero AA, Uusitalo AL, Stellingwerff T (2017) Dietary microperiodization in elite female and male runners and race walkers during a block of high intensity precompetition training. Int J Sport Nutr Exerc Metab 27:297-304

9. Doering TM, Reaburn PR, Cox G, Jenkins DG (2016) Comparison of postexercise nutrition knowledge and postexercise carbohydrate and protein intake between australian masters and younger triathletes. Int J Sport Nutr Exerc Metab 26:338-346

10. Praz C, Granges M, Burtin C, Kayser B (2015) Nutritional behaviour and beliefs of ski-mountaineers: a semi-quantitative and qualitative study. J Int Soc Sports Nutr 12:46-55

11. Gleeson $M$ (2016) Immunological aspects of sport nutrition. Immunol Cell Biol 94:117-123

12. Shipway R, Holloway I (2010) Running free: Embracing a healthy lifestyle through distance running. Perspect Public Health 130:270-276

13. da Fonseca-Engelhardt K, Knechtle B, Rüst CA, Knechtle P, Lepers R, Rosemann T (2013) Participation and performance trends in ultra-endurance running races under extreme conditions'Spartathlon'versus 'Badwater'. Extrem Physiol Med 2:15
14. Hargreaves M, Hawley JA, Jeukendrup A (2004) Pre-exercise carbohydrate and fat ingestion: effects on metabolism and performance. J Sport Sci 22:31-38

15. Sparks IM, van Rensburg DJ, Fletcher L, van Rensburg AJ (2018) A cross-sectional study of 2550 amateur cyclists shows lack of knowledge regarding relevant sports nutrition guidelines. S Afr J Sports Med 30:1-6

16. Wardenaar FC, Dijkhuizen R, Ceelen IJ, Jonk E, De Vries JH, Witkamp RF, Mensink M (2015) Nutrient intake by ultramarathon runners: Can they meet recommendations? Int J Sport Nutr Exerc Metab 25:375-386

17. Hendrie GA, Coveney J, Cox D (2008) Exploring nutrition knowledge and the demographic variation in knowledge levels in an Australian community sample. Public Health Nutr 11:1365-1371

18. Burke LM, Ross ML, Garvican-Lewis LA, Welvaert M, Heikura IA, Forbes SG, Mirtschin JG, Cato LE, Strobel N, Sharma AP, Hawley JA (2017) Low carbohydrate, high fat diet impairs exercise economy and negates the performance benefit from intensified training in elite race walkers. J Physiol 595:2785-2807

19. Tsitsimpikou C, Chrisostomou N, Papalexis P, Tsarouhas K, Tsatsakis A, Jamurtas A (2011) The use of nutritional supplements among recreational athletes in Athens, Greece. Int J Sport Nutr Exerc Metab 21:377-384

20. Devlin BL, Belski R (2015) Exploring general and sports nutrition and food knowledge in elite male Australian athletes. Int J Sport Nutr Exerc Metab 25:225-232

21. Hull MV, Jagim AR, Oliver JM, Greenwood M, Busteed DR, Jones MT (2016) Gender differences and access to a sports dietitian influence dietary habits of collegiate athletes. J Int Soc Sports Nutr 13:38

Publisher's Note Springer Nature remains neutral with regard to jurisdictional claims in published maps and institutional affiliations. 